\title{
Detecting and Managing Depressed Patients: Palliative Care Nurses' Self-Efficacy and Perceived Barriers to Care
}

\author{
Marita P. McCabe, Ph.D., FAPS, David Mellor, Ph.D., Tanya E. Davison, Ph.D., \\ David J. Hallford, B.A.(Psych)(Hons), and Denisa L. Goldhammer, DPsych(Clin)
}

\begin{abstract}
Background: Depression is a highly prevalent yet under-recognized and under-treated psychiatric illness in patients receiving palliative care. Nurses are the front-line health care professionals in these settings and are well-positioned to detect depressive symptoms and initiate pathways to care. Previous research suggests, however, that nurses' confidence and skills in relation to this task are low, and there appear to be a number of barriers within these settings that may impede nurses' engagement in this process.

Methods: To further investigate these factors, a quantitative study was carried out with 69 palliative care nurses from three palliative care services in Australia.

Results: A number of issues were identified, including the need for further training in the signs and symptoms of depression, issues around discussing depression with patients and their family members, and difficulty differentiating depressive symptoms from grief.

Conclusion: These findings provide insight into specific areas in which palliative care nurses would benefit from further training to improve detection rates for depression in this vulnerable population.
\end{abstract}

\section{Introduction}

D EPRESSION is a significant mental health issue in palliative care and is associated with an increased frequency and intensity of physical symptoms, ${ }^{1}$ increased pain, ${ }^{2}$ lower well-being, ${ }^{3}$ increased mortality, ${ }^{4}$ and hastened desire to die. . $^{5,6}$

The prevalence of diagnosable clinical depression in patients receiving palliative care is currently estimated at $25 \%,{ }^{7}$ with other studies reporting that up to $50 \%$ of terminally ill patients experience clinically significant depressive symptomatology that affects their quality of life. ${ }^{8,9}$ Despite this high prevalence, research has shown that detection rates are quite low, with up to $50 \%$ of depressed patients in these settings remaining undiagnosed and untreated. $6,10,11$

Due to the high level of contact that nurses have with patients in their care they are well-positioned to recognize depressive symptoms, provide pathways for treatment, and support depressed patients and their family members. Accordingly, the need for depression training for nurses in these settings has been recommended. ${ }^{12}$ Despite these nurses recognizing depression as a common issue and identifying the need for further training, ${ }^{13}$ a minority of nurses actually receive specialized training in working with depressed patients and their families, ${ }^{13,14}$ and there exist few evaluated training interventions. $^{15}$

If these training interventions within palliative services are to be effective, they must target areas in which nurses have difficulty, and provide education or training relating to specific barriers to care. To date, several factors that relate to nurses' confidence and skills in working with depressed patients, and barriers to providing pathways to treatment, have been recognized. Among these are a limited knowledge of depressive symptoms, ${ }^{13}$ an over-reliance on less reliable somatic symptoms of depression that overlap with patients' medical conditions, ${ }^{13,14}$ and infrequent use of systematic instruments for screening. ${ }^{16}$ Nurses' perceived lack of confidence $^{17}$ and time ${ }^{16}$ to discuss emotional issues with patients, as well as broader concerns regarding the stigma surrounding depression, also present potential obstacles to effective recognition of depression in these settings. ${ }^{18}$ Furthermore, the difficulty in differentiating clinical depression from grief reactions represents another potential barrier to the recognition of depressive symptoms and ultimately the provision of pathways to care. ${ }^{19}$

Although the broader palliative care literature has indentified areas in which nurses may need further training, survey data on nurses' own perceptions of their confidence and skills and the barriers to providing pathways to care for 
depressed patients are currently lacking. Although there exist some data on nurse reports, ${ }^{13,14}$ in general this has not been well-documented. Further clarification is therefore required of the specific areas in which training would be of benefit to nurses, so as to better inform future interventions aimed at palliative care services. Against this background, the current study aimed to describe palliative care nurses' confidence and skills, as well as their perception of the barriers to working with depressed patients. Questionnaires evaluating these variables were developed and distributed to palliative care nurses as part of a larger study designed to implement and evaluate a training program for professional carers working in palliative care settings. For a study protocol see Hallford et al. ${ }^{15}$ The current study reports these nurses' responses relating to their perceived confidence in areas pertaining to the detection and provision of care for depressed patients, and issues they identified as barriers to this process.

\section{Methods}

\section{Participants}

Questionnaires were completed by 69 nurses aged 21 to 65 years (mean age $=45.55$, standard deviation $[S D]=9.17$ ) who work in three regional health service palliative care settings in the state of Victoria, Australia. Participants reported a mean of 9.14 years $(\mathrm{SD}=7.83)$ of experience working in palliative care (range $=0.08$ to 30$)$. Of the participants, $71 \%(n=49)$ reported working in an inpatient palliative care setting, and $27.6 \%$ $(n=19)$ reported working in a community palliative care setting. One participant $(1.4 \%, n=1)$ indicated working across both hospital and community settings. In total, $34.8 \%(n=24)$ participants reported having received previous training in depression. Of those who had received depression training, $51.6 \%(n=16)$ indicated this was part of a formal training course, $22.6 \%(n=7)$ received training at their current workplace, $25.8 \%(n=8)$ reported "other" ways, and four did not provide information. The remaining $63.8 \%(n=44)$ of participants reporting no previous depression training, and $1.4 \%$ $(n=1)$ did not respond to this question. Of those who were approached to take part in the study, $84 \%$ of nurses agreed to participate.

\section{Materials}

Participants provided demographic details and responded on a 4-point Likert scale ranging from 1 (strongly disagree) to 4 (strongly agree) to statements regarding the perceived prevalence of depression in palliative care settings, "Depression is common among people receiving palliative care" and the perceived rates of detection, "It is common for depression to go undetected among people receiving palliative care."

Self-efficacy (confidence and skills) in working with depressed patients. A 16-item questionnaire, "SelfEfficacy in Detecting and Managing Depression in Palliative Care Settings" (see Table 1), evaluated nurses' level of selfefficacy in a number of areas, such as their knowledge of depression and ability to communicate with depressed palliative care recipients. This scale was constructed from a pool of items created by the researchers and based on a range of barriers identified from a literature review, as well as items modified to be appropriate for a palliative care setting from a
Table 1. Nurses' Responses to Questions about Self-EfFicacy in Working With Depressed Patients Ordered from Least to Most Confident

\begin{tabular}{lcc}
\hline Item & $\begin{array}{c}\text { Low } \\
\text { confidence } \\
(\%)\end{array}$ & $\begin{array}{c}\text { High } \\
\text { confidence } \\
(\%)\end{array}$ \\
\hline Differentiating between a patient & $37(54 \%)$ & $32(46 \%)$
\end{tabular}

who might be depressed, or is responding with grief to their current situation.

My ability to inform and educate $32(46 \%) \quad 37(54 \%)$ patients and their family members about depression.

Telling the difference between signs of depression and anxiety.

Understanding of how depression affects patients.

Responding to depressionrelated or desire-to-die statements.

Supporting family members of depressed patients.

Monitoring signs of depression among patients to see if things improve or become worse.

Being able to recognize that a patient might be depressed.

Knowing what the signs and symptoms of depression are.

Discussing referral or support options for depression with a patient.

Overall, in providing care for patients with depression.

Knowing when it is time to raise concerns about a patient who might be depressed.

Asking family members about their feelings or mood.

Asking patients about their feelings or mood.

Listening to patients talk about their feelings or mood.

Consulting with other staff members about patients' psychological well-being.

$31(45 \%) \quad 38(55 \%)$

$26(38 \%)$

$43(62 \%)$

$26(38 \%) \quad 43(62 \%)$

$22(32 \%)$

$47(68 \%)$

$22(32 \%)$

$47(68 \%)$

$22(32 \%)$

$47(68 \%)$

$19(28 \%)$

$50(72 \%)$

18 (26\%)

$51(74 \%)$

$18(26 \%)$

$51(74 \%)$

$17(25 \%)$

$52(75 \%)$

$16(23 \%)$

$53(77 \%)$

$10(15 \%)$

$59(85 \%)$

$4(6 \%)$

$65(94 \%)$

$4(6 \%)$

$65(94 \%)$

scale originally developed to assess the self-efficacy of care staff working with depression in the aged care sector. ${ }^{20}$ The items in this scale were checked with four staff members working in a palliative care setting for their relevance and clarity of wording. Responses were answered using a 4-point Likert scale ( $1=$ not at all confident; 2 =slightly confident; $3=$ mostly confident; $4=$ very confident). The internal reliability of this scale was high, with a Cronbach $\alpha=0.94(95 \%$ confidence interval [CI] 0.91-0.96).

Perceived barriers to working with depressed patients. The "Barriers to Detecting and Managing Depression in Palliative Care Settings" is a 12-item scale (see Table 2), constructed from a pool of items created by the authors of the current article and based on a range of barriers identified from 
Table 2. Nurses' Responses to Questions about Perceived Barriers to Working with Depressed Patients

\begin{tabular}{|c|c|c|}
\hline Item & $\begin{array}{l}\text { Staff who agree } \\
\text { it is a barrier }(\%)\end{array}$ & $\begin{array}{l}\text { Staff who disagree } \\
\text { it is a barrier }(\%)\end{array}$ \\
\hline $\begin{array}{l}\text { Reluctance of some patients and family members to discuss how they } \\
\text { feel make it difficult to identify if they are depressed. }\end{array}$ & 59 (85\%) & $10(15 \%)$ \\
\hline $\begin{array}{l}\text { Difficult to differentiate whether some patients are presenting with } \\
\text { grief or clinical depression. }\end{array}$ & $56(81 \%)$ & $13(19 \%)$ \\
\hline $\begin{array}{l}\text { I do not have a systematic way to monitor patients' depressive } \\
\text { symptoms. }\end{array}$ & 49 (71\%) & $20(29 \%)$ \\
\hline $\begin{array}{l}\text { Difficult to detect/monitor depression because patients often mask } \\
\text { their depressive symptoms. }\end{array}$ & $48(70 \%)$ & $21(30 \%)$ \\
\hline $\begin{array}{l}\text { Difficult to detect depression because of the overlap in depressive } \\
\text { symptoms and the physical symptoms related to a patient's medical } \\
\text { condition. }\end{array}$ & $45(65 \%)$ & $24(35 \%)$ \\
\hline $\begin{array}{l}\text { Difficult to detect depression because I do not have enough } \\
\text { knowledge of its signs and symptoms. }\end{array}$ & $44(64 \%)$ & $25(36 \%)$ \\
\hline $\begin{array}{l}\text { Inadequate communication between staff members in my workplace } \\
\text { means that depression is not always managed as effectively as it } \\
\text { could be. }\end{array}$ & $44(64 \%)$ & $25(36 \%)$ \\
\hline $\begin{array}{l}\text { I have not received enough training in depression to recognize } \\
\text { whether a patient is depressed or not. }\end{array}$ & $43(62 \%)$ & $26(38 \%)$ \\
\hline $\begin{array}{l}\text { I do not have enough time to talk with patients and their family } \\
\text { members in order to detect depression. }\end{array}$ & $41(59 \%)$ & $28(41 \%)$ \\
\hline $\begin{array}{l}\text { I am not very familiar with resources/support services for depression } \\
\text { to which patients and their family members can be directed. }\end{array}$ & $39(56 \%)$ & $30(44 \%)$ \\
\hline $\begin{array}{l}\text { My limited knowledge of how to support depressed patients means } \\
\text { that they may not always receive the best management for their } \\
\text { illness. }\end{array}$ & $34(49 \%)$ & $35(51 \%)$ \\
\hline $\begin{array}{l}\text { The stigma associated with depression makes it difficult to talk about } \\
\text { such issues with patients and their family members. }\end{array}$ & $33(48 \%)$ & $36(52 \%)$ \\
\hline
\end{tabular}

a literature review. As for the self-efficacy scale, the items in this scale were checked with four professionals from a palliative care setting to determine their relevance and clarity of wording. Responses were recorded on a 4-point Likert scale (1=strongly disagree; 2 =somewhat disagree; 3 =somewhat agree; $4=$ strongly agree). The internal reliability of this scale was good, with a Cronbach $\alpha=0.80$ (95\% CI 0.72-0.86).

\section{Procedure}

Ethics approval was granted from the University Research Ethics Committee, as well as the Research Ethics committees of the three palliative care services from which participants were recruited. These services were located in an urban, regional, and rural setting, and included a range of palliative care services: primarily hospital based, primarily community based, and a mix of hospital- and community-based care. Questionnaires incorporating these reported items and measures of self-efficacy and perceived barriers to care were distributed to palliative care nurses to complete as part of the baseline measures of another study. ${ }^{15}$ No incentives were offered for participatation.

\section{Analytic strategy}

The items in each of the scales described above were analyzed as separate items, rather than as a total scale score. This strategy allowed us to determine the specific perceived strengths and weaknesses of staff in relation to their confidence and skills, as well as the specific barriers to working with depressed patients. To better interpret these findings, the data were collapsed into low confidence and high confidence (for self-efficacy) and perceived to be a barrier or not a barrier (for barriers). The specific manner in which these categories were determined is described below.

Responses to the items "Depression is common among people receiving palliative care" and "It is common for depression to go undetected among people receiving palliative care" were split by coding responses of "strongly disagree" and "somewhat disagree" as "disagree" and responses of "somewhat agree" and "strongly agree" as "agree." The results showed that $87 \%(n=60)$ of nurses agreed that depression was common among people receiving palliative care. In total, $81.2 \%$ $(n=56)$ of nurses agreed that it was common for depression to go undetected among people receiving palliative care.

Participants' responses to the "Self-Efficacy in Detecting and Managing Depression in Palliative Care Settings" scale were split by coding responses of "not at all confident" and "slightly confident" as "low confidence," and responses of "mostly confident" and "very confident" as "high confidence." Responses to the "Barriers to Detecting and Managing Depression in Palliative Care Settings" scale were also split by coding responses of "strongly disagree" and "somewhat disagree" as "disagree it is a barrier," and responses of "somewhat agree" and "strongly agree" as "agree it is a barrier." Tables 1 and 2 show the frequency of participant responses according to this coding of responses.

\section{Results}

Approximately one-third of nurses reported low confidence in recognizing depression, knowing what the signs and 
symptoms are, and understanding its effects. Furthermore, almost two-thirds of nurses endorsed a lack of training and knowledge of signs and symptoms as barriers to detecting depression among their patients. One-third of nurses indicated that they were not confident in monitoring symptoms of depression in their patients. A large majority of nurses reported feeling confident in both listening to and asking patients and their family members about their feelings or mood.

There was a reported reluctance among patients to discuss depression and a high reported level of masking of depressive symptoms. Almost half of the nurses reported that stigma surrounding depression was a barrier to detection, and did not feel confident informing and educating patients and their families about depression. Whereas nurses felt extremely confident about communicating with fellow staff members about their patients' psychological well-being, almost twothirds also felt that there was an inadequate amount of this communication and that this compromised the management and support of depressed patients. Although the majority of nurses felt confident discussing referral or support options with patients, almost half felt that a lack of knowledge about these resources was a barrier to care. Three quarters of nurses felt confident in providing care to patients who were already recognized as depressed. However, nurses identified differentiating depression from grief and anxiety as particularly difficult.

\section{Discussion}

The current study investigated palliative care nurses' selfefficacy and perceived barriers to detecting and providing care for depressed patients. Consistent with previous research, ${ }^{13}$ nurses reported perceiving depression as common in palliative care settings. Moreover, a large majority also reported that it was common for this depression to go unnoticed, providing evidence for a pervasive awareness among nurses of the low rates of detection and treatment in these settings. Indeed, the consistent agreement on a wide range of barriers to recognizing and providing care for depressed patients indicated that awareness of the difficulties inherent in this process resonated strongly among these nurses. A number of themes arising from these nurses' response patterns are discussed next.

\section{Knowledge and detection of depression}

Interpreted alongside nurses' reports that depression is often undetected in these settings, the findings related to low confidence and a lack of training in this area are consistent with previous research. ${ }^{13,14}$ One issue previously identified as compromising nurses' ability to detect depression is their reliance on somatic symptoms such as fatigue, sleep disturbance, and poor appetite, ${ }^{13}$ despite their poor specificity as indicators of depression among palliative care patients. ${ }^{21}$ Given that the overlap between depressive symptoms and physical symptoms related to a patients' medical condition was also identified by nurses as a major barrier to detection, these findings reiterate the need for wider understanding and use of the potentially more reliable mood and cognitiverelated markers of depression in this setting.

Consistent with previous findings, ${ }^{16}$ the lack of a systematic method of monitoring depression was strongly identified as a barrier to the treatment of depression. Although research has provided evidence for the utility of validated tools for screening and monitoring depression in these settings, ${ }^{22,23}$ integrating their use into practice appears to be a challenge currently faced by palliative care services.

\section{Discussing depression}

Although the reported confidence in discussing depression with both patients and the family appears promising, nurses also clearly identified a reluctance among patients in their care to discuss these issues. Nurses reported that many patients mask symptoms of depression. In addition, nurses' reported low confidence in responding to desire-to-die or depressionrelated statements, and a lack of time to talk with patients and family members were barriers to recognizing when a patient may be depressed.

The findings related to stigma associated with depression are consistent with palliative care staffs' reported difficulties in directly discussing negative emotional issues, ${ }^{18,24}$ and their belief that discussing depression directly may make it worse. ${ }^{14}$ These responses suggest that further training in how to sensitively and effectively broach and normalize psychological issues to increase the probably of patients disclosure and detection of depression may assist nurses in these settings.

Although finding time to discuss patients' psychological functioning with other staff members may be difficult within busy palliative care services, this sharing of information can provide a more reliable picture of patients' mental health. A lack of knowledge of support services may compromise nurses' ability to advise patients and their family members of the range of pathways to care available to them, particularly within community-based services where external support services may play a larger role.

\section{Differentiating depression and providing support}

The problem experienced by nurses in differentiating depression from grief highlights the potential for many depressed patients to be mistakenly perceived as going through a natural grief response that is common to these settings. This is particularly concerning given that some nurses perceive depression as a typical or "natural" reaction to terminal illness. ${ }^{14}$ These findings provide evidence that the process of distinguishing between symptoms of grief and depression, although widely documented in the research and academic literature, ${ }^{19,25}$ may not be well disseminated or understood among nurses working in these settings and represents an important area to address in training palliative care nurses. Although many of the nurses were confident in recognizing those patients who were depressed, they noted several specific barriers that may impede the provision of effective care of these patients, such as limited knowledge of management strategies for depression, and low confidence in providing support for family members and informing and educating those in their care about depression.

\section{Conclusion}

The results of this study need to be treated with caution, as the scales that were used to gather the data have not previously been validated in the palliative care setting. Further validation work with the scales is required. However, the 
findings do demonstrate that if depression is to be detected and managed effectively in palliative care settings, then training for nurses, and indeed other health care staff, must be both informed and pragmatic. The current study identifies a number of issues that may account for the low rates of detection of depression in these settings. These findings can assist in future endeavors to inform specialized training in depression.

\section{Author Disclosure Statement}

No competing financial interests exist.

\section{References}

1. Delgado-Guay M, Parson HA, Li Z, Palmer L, Bruera, E: Symptom distress in advanced cancer patients with anxiety and depression in the palliative care setting. Support Care Cancer 2009;17:573-579.

2. Jung S, Park K, Kim J, Do Y, Kwon K, Song H, Koh S: Prevalence of emotional distress, anxiety and depression and their impact on pain in terminally ill cancer patients. J Clin Oncol 2010;28:e19642.

3. Smith EM, Gomm SA, Dickens CM: Assessing the independent contribution to quality of life from anxiety and depression in patients with advanced cancer. Palliat Med 2003;17:509-513.

4. Lloyd-Williams M, Shiels C, Taylor F, Dennis M: Depression-an independent predictor of early death in patients with advanced cancer. J Affect Disord 2009;114:127-132.

5. Breitbart W, Rosenfeld B, Gibson C, Kramer M, Li Y, Tomarken A, Nelson C, Pessin H, Esch J, Galietta M, Garcia N, Brechtl J, Schuster M: Impact of treatment for depression on desire for hastened death in patients with advanced AIDS. Psychosomatics 2010;52:98-105.

6. O'Mahony S, Goulet J, Kornblith A, Abbatiello G, Clarke B, Kless-Siegel S, Breitbart W, Payne R: Desire for hastened death, cancer pain and depression: Report of a longitudinal observational study. J Pain Symptom Manage 2005;29:446-457.

7. Mitchell AJ, Chan M, Bhatti H, Halton M, Grassi L, Johansen C, Meader N: Prevalence of depression, anxiety, and adjustment disorder in oncological, haematological, and palliative-care settings: A meta-analysis of 94 interview-based studies. Lancet Oncol 2011;2:160-174.

8. O'Connor M, White K, Kristjanson LJ, Cousins K, Wilkes L: The prevalence of anxiety and depression in palliative care patients with cancer in Western Australia and New South Wales. Med J Aust 2010;193:S44-S77.

9. Reeve JL, Lloyd-Williams M, Dowrick C: Revisiting depression in palliative cares settings: The need to focus on clinical utility over validity. Palliat Med 2008;22:383-391.

10. Irwin SA, Rao S, Bower K, Palica J, Roa SJ, Maglione JE, Soskins M, Betterton AE, Ferris FD: Psychiatric issues in palliative care: Recognition of depression in patients enrolled in hospice care. J Palliat Med 2008;1:158-163.

11. Wilson KG, Chochinov HM, Skirko MG: Depression and anxiety disorders in palliative cancer care. J Pain Symptom Manage 2007;33:118-129.
12. Stiefel F, Trill MD, Berney A, Olarte JMN, Razavi D: Depression in palliative care: A pragmatic report from the Expert Working Group of European Association for Palliative Care. Support Care Cancer 2001;9:477-488.

13. Lloyd-Williams M, Payne S: Nurse specialist assessment and management of palliative care patients who are depressed-a study of perceptions and attitudes. J Palliat Care 2002;18: 270-274.

14. Lloyd-Williams M, Payne S: A qualitative study of clinical nurse specialist views on depression in palliative care patients. Palliat Med 2003;17:334-338.

15. Hallford D, McCabe MP, Mellor D, Davison TE, Goldhammer D, George K, Storer S: Intervention for depression among palliative care patients and their families: A study protocol for evaluation of a training program for professional care staff. BMC Palliat Care 2011;10:11.

16. Mitchell AJ, Kaar S, Coggan C, Herdman J: Acceptability of common screening methods used to detect distress and related mood disorders-preferences of cancer specialists and non-specialists. Psychooncology 2008;3:226-236.

17. Lloyd-Williams M. Screening for depression in palliative care patients: A review. Eur J Cancer Care 2001;10:31-35.

18. Endo C, Akechi T, Okuyama T, Seto T, Kato M, Seki N, Eguchi K, Hosaka T, Furukawa TA: Patient-perceived barriers to the psychological care of Japanese patients with lung cancer. J Clin Oncol 2008:38:653-660.

19. Noorani NH, Montagnini M: Recognising depression in palliative care patients. J Palliat Med 2007;10:458-464.

20. McCabe MP, Russo S, Mellor D, Davison TE, George K: Effectiveness of a training program for carers to recognise depression among older people. Int J Geriatr Psychiatry 2008;23:1290-1296.

21. Hotopf M, Lee W, Price A, Monroe B: The clinical epidemiology of depression in palliative care and the predictive value of somatic symptoms. Palliat Med 2010;25:1-13.

22. Rao S, Ferris FD, Irwin SA: Ease of screening for depression and delirium in patients enrolled in inpatient hospice care. J Palliat Med 2011;14:275-279.

23. Rayner L, Loge JH, Wasteson E, Higginson IJ: The detection of depression in palliative care. Curr Opin Support Palliat Care 2009;3:55-60.

24. Malloy P, Virani R, Kelly K, Manuver C: Beyond bad news: Communication skills of nurses in palliative care. J Hospice Palliat Nur 2010;12:166-174.

25. Periyakoil JS, Hallenbeck J: Identifying and managing preparatory grief and depression at the end of life. Am Fam Physician 2002;65:883-890.

Address correspondence to: Marita P. McCabe, Ph.D., FAPS

Deakin University School of Psychology 221 Burwood Highway Burwood, Victoria 3125

Australia

E-mail: marita.mccabe@deakin.edu.au 